\section{Commentary: To operate or wait? Contextualizing early outcomes of cardiac surgery in COVID-19- positive patients}

\author{
Sameer A. Hirji, MD, MPH, \\ Cheryl K. Zogg, PhD, MSPH, MHS, ${ }^{\mathrm{b}}$ and \\ Tom C. Nguyen, MD
}

The global outbreak of SARS-CoV-2 led to widespread disruption of elective surgical procedures. In the context of cardiac surgery, it dramatically reduced the nationwide operative case volume by more than $50 \%$ and created a backlog of deferred cardiac surgeries, according to recent data from the Society of Thoracic Surgeons (STS) Adult Cardiac Surgery Database (ACSD). ${ }^{1}$ As a consequence, hospitals are left to grapple with how best to prepare for "postpandemic planning" in the midst of infection while simultaneously facing an increasing number of patients forced to prolong their disease course and wait. In their brief communication in this issue of the Journal, the Cardiothoracic Interdisciplinary Research Network and COVIDSurg Collaborative $^{2}$ seek to help hospitals address this issue by studying the outcomes of 155 preoperatively and 52 postoperatively diagnosed cases of COVID-19 patients who underwent cardiac surgery between March 1 and July 31, 2020. The study found no significant difference in the incidence of mortality $(15.4 \%$ vs $21.9 \%$ ) or major morbidity (except pneumonia: $28.8 \%$ vs $46.6 \%$ ) between COVID-19 patients diagnosed within 7 days of surgery compared to 30 days

\footnotetext{
From the ${ }^{a}$ Division of Cardiac Surgery, Department of Surgery, Brigham and Women's Hospital, Harvard Medical School, Boston, Mass; ' $Y a$ le School of Medicine, New Haven, Conn; and ${ }^{\mathrm{c}}$ Division of Cardiothoracic Surgery, Department of Surgery, University of San Francisco, San Francisco, Calif.

Drs Hirji and Zogg should be considered co-first authors.

Disclosures: Dr Hirji is a consultant for the Encare EIAS system. Dr Nguyen is a consultant for Edwards Lifesciences and LivaNova. Dr Zogg reported no conflicts of interest.

The Journal policy requires editors and reviewers to disclose conflicts of interest and to decline handling or reviewing manuscripts for which they may have a conflict of interest. The editors and reviewers of this article have no conflicts of interest.

Received for publication April 20, 2021; revisions received April 20, 2021; accepted for publication April 22, 2021; available ahead of print April 27, 2021.

Address for reprints: Tom C. Nguyen, MD, Division of Cardiothoracic Surgery, Department of Surgery, University of California San Francisco, 500 Parnassus Ave, San Francisco, CA 94143 (E-mail: tom.c.nguyen@gmail.com).

J Thorac Cardiovasc Surg 2021;162:e373-4

$0022-5223 / \$ 36.00$

Copyright (C) 2021 by The American Association for Thoracic Surgery

https://doi.org/10.1016/j.jtcvs.2021.04.059
}

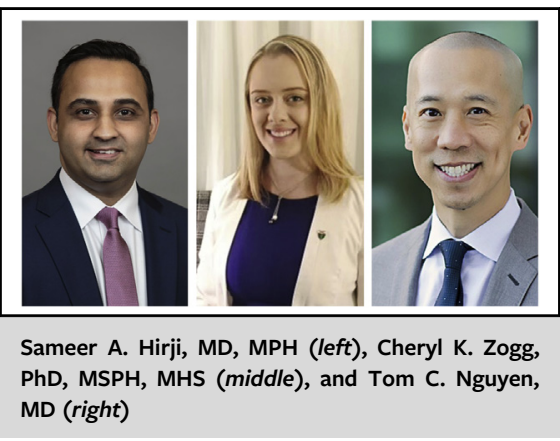

CENTRAL MESSAGE

COVID-19 infection increases the risk of cardiac surgery, and caution is warranted to balance operative need with safe procedures during a patient's entire disease course.

after surgery - a finding that led them to argue for the importance of ensuring that adult cardiac surgery patients are managed postoperatively on "COVID clean" pathways and wards to minimize the risk of postoperative infection and related sequalae.

We commend the work coordinated by the COVIDSurg Collaborative in collecting this vital information from their multicenter cohort. These results represent one of the largest case series of cardiac surgery outcomes among COVID-19-positive patients published to date, offering important insights into the need to minimize the perioperative risk of SARS-CoV-2 infection. It builds on prior work from the COVIDSurg Collaborative, which showed that among all COVID-19-positive patients, delaying surgery by $\geq 7$ weeks after SARS-CoV-2 diagnosis was associated with reduced mortality back to preinfection levels. ${ }^{3}$ Both studies suggest that operating on a COVID-19-positive patient increases the patient's risk of death. ${ }^{2,3}$ These findings are also corroborated in the recent analysis of the STS ACSD, which showed a $110 \%$ increase in the odds to expected ratio for all adult cardiac procedures during this study period.

As hospitals begin reopening operating room doors to the mounting backlog of patients awaiting elective procedures, guidelines from organizations like the STS and the American Association for Thoracic Surgery (AATS) may offer a reasonable approach centered around the importance of protecting the cardiac patient, the institution and 
society at large, and the health care team. ${ }^{4}$ Modeling studies from throughout the pandemic have further emphasized that it will take time for hospitals to clear their backlog, depending on their respective operative capacity in the post-COVID period ${ }^{5}$ and the potential consequences that waiting could have on patients requiring more urgent operative care. We believe that a stepwise/tiered reopening approach that focuses on minimizing infection risk is prudent and will simultaneously ensure that patients in need of care are not endlessly caught in the crosshairs of surgeons' and hospitals' struggle with how best to answer the difficult question of when is the right time to operate or wait.

\section{References}

1. Nguyen TC. Impact of COVID-19 on adult cardiac surgery: an analysis of the STS ACSD. Presented at: The 57th Annual Meeting of the Society of Thoracic Surgeons, January 29-31, 2021 [virtual].

2. Cardiothoracic Interdisciplinary Research Network, COVIDSurg Collaborative. Early outcomes and complications following cardiac surgery in patients testing positive for coronavirus disease 2019: an international cohort study. J Thorac Cardiovasc Surg. 2021;162:e355-72.

3. COVIDSurg Collaborative, GlobalSurg Collaborative. Timing of surgery following SARS-CoV-2 infection: an international prospective cohort study. Anaesthesia. 2021;76:748-58.

4. Haft JW, Atluri P, Ailawadi G, Engelman DT, Grant MC, Hassan A, et al. Adult cardiac surgery during the COVID-19 pandemic: a tiered patient triage guidance statement. J Thorac Cardiovasc Surg. 2020;160:452-5.

5. Salenger R, Etchill EW, Ad N, Matthew T, Alejo D, Whitman G, et al. The surge after the surge: cardiac surgery post-COVID-19. Ann Thorac Surg. 2020;110: 2020-5.
See Article page e355.

\section{Commentary: Cardiac surgery in COVID patients: Figuring it out as}

\section{we go}

\author{
Sarah A. Clark, MD, and Nicholas R. Teman, MD
}

Since the outbreak of the novel SARS-CoV-2 (COVID-19) viral pandemic in late 2019, the entire world has had to make decisions, ranging from how to treat the profound respiratory complications of COVID-19 pneumonia to how to maintain a globalized economy with significant travel and trade restrictions, based on very limited information. Despite our limited knowledge of this disease, many of those decisions have had an enormous impact on our dayto-day lives, forcing everyone to grapple with uncertainty and changing norms. Although our knowledge of this virus and how to manage it has grown exponentially over the last year, this brief communication by the Cardio-Thoracic

From the Division of Cardiac Surgery, University of Virginia Health System, Charlottesville, Va.

Disclosures: The authors reported no conflicts of interest.

The Journal policy requires editors and reviewers to disclose conflicts of interest and to decline handling or reviewing manuscripts for which they may have a conflict of interest. The editors and reviewers of this article have no conflicts of interest.

Received for publication April 19, 2021; revisions received April 19, 2021; accepted for publication April 20, 2021; available ahead of print April 27, 2021.

Address for reprints: Nicholas R. Teman, MD, Division of Cardiac Surgery, University of Virginia Health System, PO Box 800679, 1215 Lee St, Charlottesville, VA 22908 (E-mail: NRT4C@virginia.edu).

J Thorac Cardiovasc Surg 2021;162:e374-5

$0022-5223 / \$ 36.00$

Copyright (c) 2021 by The American Association for Thoracic Surgery

https://doi.org/10.1016/j.jtcvs.2021.04.058
Check for updates

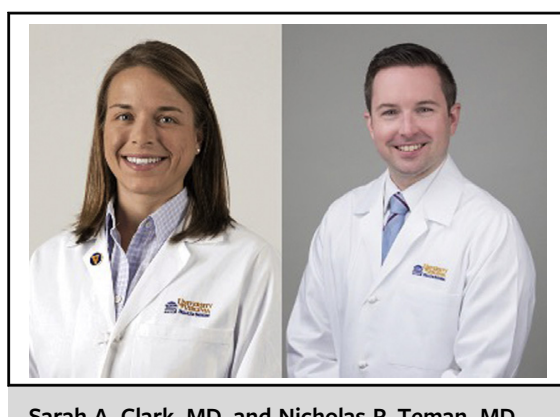

Sarah A. Clark, MD, and Nicholas R. Teman, MD

CENTRAL MESSAGE

COVID infection in patients undergoing cardiac surgery is associated with significant morbidity and mortality, but more information is needed to guide clinical decision making.

Interdisciplinary Research Network and COVIDSurg Collaboration serves as a reminder of how little we know about COVID-19 and its sequelae.

In this multicenter international observational cohort study, unadjusted outcomes of patients undergoing cardiac surgery with known COVID-19 infection within the perioperative period ( 7 days preoperatively up to 30 days postoperatively) were examined. Patients who contracted COVID-19 in the perioperative period exhibited higher than normal rates of respiratory complications, including prolonged mechanical ventilation and pneumonia. ${ }^{2}$ The authors also report 